\title{
REVIEW
}

\section{An Overview of the Derivation and Function of Multinucleated Giant Cells and Their Role in Pathologic Processes}

\author{
Patricia J. Brooks, ${ }^{{ }^{\dagger}}$ Michael Glogauer, ${ }^{* \dagger}$ and Christopher A. McCulloch* \\ From the Matrix Dynamics Group, ${ }^{*}$ University of Toronto, Toronto; and the Department of Dental Oncology and Maxillofacial Prosthetics, ${ }^{\dagger}$ Princess \\ Margaret Cancer Centre, Toronto, Ontario, Canada
}

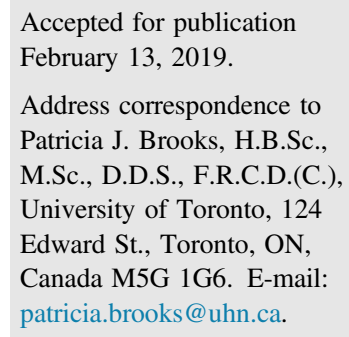

\begin{abstract}
Monocyte lineage cells play important roles in health and disease. Their differentiation into macrophages is crucial for a broad array of immunologic processes that regulate inflammation, neoplasia, and infection. In certain pathologic conditions, such as foreign body reactions and peripheral inflammatory lesions, monocytes fuse to form large, multinucleated giant cells (MGCs). Currently, our knowledge of the fusion mechanisms of monocytes and the regulation of MGC formation and function in discrete pathologies is limited. Herein, we consider the types and function of MGCs in disease and assess the mechanisms by which monocyte fusion contributes to the formation of MGCs. An improved understanding of the cellular origins and metabolic functions of MGCs will facilitate their identification and ultimately the treatment of diseases and disorders that involve MGCs. (Am J Pathol 2019, 189: 1145-1158; https://doi.org/10.1016/j.ajpath.2019.02.006)
\end{abstract}

Certain healthy tissues, including skeletal muscle, placenta, and bone, contain populations of multinucleated cells. ${ }^{1}$ In contrast, the presence of multinucleated cells in other tissues is considered pathologic. Multinucleated giant cells (MGCs), which are polykaryons of monocytic origin, are often spatially associated with foreign bodies (ie, introduced exogenous materials) or comprise part of a tissue response to infection. MGCs also appear in autoimmune, neoplastic, and genetic disorders. Histologically, MGCs are morphologically similar to one another, despite their appearance in various discrete pathologies. Currently, the characterization of the various types of MGCs by histology alone is of limited value as the molecular determinants that specify the formation and function of these cells are not defined.

Although multinucleated cells of other origins exist in some pathologies, only those of monocytic origin will be discussed herein. Under the influence of specific cytokines and signaling molecules, monocytes can differentiate into discrete subtypes, macrophages and preosteoclasts. These more specialized cells can then undergo multiple fusion events to form multinucleated cells. Despite advances in the understanding of monocyte differentiation, the relationship between various monocyte and macrophage subtypes and the different MGCs that they form is not defined. We focus herein on discrete, MGC-containing lesions and consider the fusion mechanisms and molecules involved in MGC formation. An in-depth understanding of the monocyte and macrophage subtypes that contribute to MGC formation in various pathologic conditions and the expression of molecules that enable cell fusion could lead to better diagnostic approaches through application of disease-specific MGC markers and new molecular targets for MGC-focused therapies.

\section{Multinucleated Giant Cells in Pathology}

MGCs exhibit similar morphologies under light microscopy but arise in pathologic lesions of widely varying etiology

\footnotetext{
Supported by a Queen Elizabeth II Graduate Scholarship in Science and Technology (P.J.B.), the Princess Margaret Cancer Centre Research Foundation (M.G.), and the Canada Research Chair in Matrix Dynamics and Canadian Institutes of Health Research operating grant MOP36332 (C.A.M.).

Disclosures: None declared.
} 
(Figure 1). The diagnostic workup of giant cell-rich lesions can be challenging despite a priori information about patient demographics, anatomic location, and radiographic interpretation. ${ }^{2}$ Currently, there is little understanding of MGC subtypes, which complicates the differential diagnosis of giant cell-rich lesions. Herein, we describe MGC-rich lesions based on their molecular expression profiles and proposed cell fusion mechanisms (Table 1). ${ }^{3-17}$ We focus on lesions of high prevalence that are associated with complex diagnoses and uncertainty of the pathogenic mechanisms that lead to their development.

\section{Lesions Containing OCLGCs}

The osteoclast-like giant cell (OCLGC) is a large, multinucleated cell with dispersed nuclei in a pale cytoplasm. These cells exhibit similar phenotypic markers as osteoclasts, ${ }^{18}$ but they are not always found on bone surfaces. Lesions that contain large numbers of OCLGCs but without other defining histologic characteristics are assigned to this diagnostic group.

Giant Cell Tumor, Aneurysmal Bone Cyst, and Osteosarcoma The giant cell tumor of bone and the aneurysmal bone cyst are MGC-rich lesions of neoplastic origin. Giant cell tumors of bone display locally aggressive behavior and are composed of large numbers of OCLGCs, spindle-shaped stromal cells, and epithelioid-shaped mononuclear cells. In contrast, aneurysmal bone cysts contain blood-filled cavities that are lined by fibrous septa with more scarce and scattered MGCs. ${ }^{18}$ A mutation in the H3F3A gene (found in $92 \%$ of giant cell tumors ${ }^{2}$ ) induces the neoplastic spindle cells to drive reactive formation of OCLGCs. This process results from spindle cell secretion of monocyte chemoattractant protein and macrophage colony-stimulating factor, which promote monocytic cell recruitment and differentiation into preosteoclasts. Spindle cells also express receptor activator of NF- $\mathrm{KB}$ ligand (RANKL), which acts on RANK-expressing preosteoclasts to promote cell fusion. Cytogenetic abnormalities have been identified in all primary aneurysmal bone cysts. These abnormalities involve the ubiquitin-specific protease 6 and osteoblast cadherin 11, along with others. ${ }^{19}$ Expression of these molecules attenuates osteoblastic maturation, which is associated with increased osteoclastogenesis arising from the expression of RANKL by osteoblasts.

OCLGCs are also found in malignancies of bone. Indeed, one-quarter of osteosarcomas (commonly the telangiectatic and giant cell-rich variants) contain MGCs. ${ }^{20}$ Osteoclastogenesis in these lesions involves aberrant RANKL expression by malignant osteoblasts. All three of these lesions contain MGCs that express the osteoclast markers tartrate-resistant acid phosphatase, vacuolar ATPases, carbonic anhydrase II, cathepsin K, and matrix metalloproteinase-9 (Table 1). As these proteins are involved in bone demineralization and collagen degradation, ${ }^{3,20}$ and in view of their location on bone surfaces, MGCs in these lesions are probably involved in bone resorption. Accordingly, OCLGCs likely contribute to the growth and expansion of the lesions by invasion through bone. Denosumab, an antibody that neutralizes RANKL, inhibits the formation and activity of MGCs and is approved for treatment of inoperable giant cell tumors of bone and of sarcomas to decrease tumor-induced osteolysis. ${ }^{5,21}$

\section{Cherubism and Brown Tumor of Hyperparathyroidism}

Herein, we consider the MGCs of cherubism and brown tumor of hyperparathyroidism together as they are manifestations of systemic conditions, and patients may present with multiple lesions. Cherubism is a mainly autosomal dominant disorder, characterized by bilateral, centralized giant cell lesions of the maxillae that produce substantial
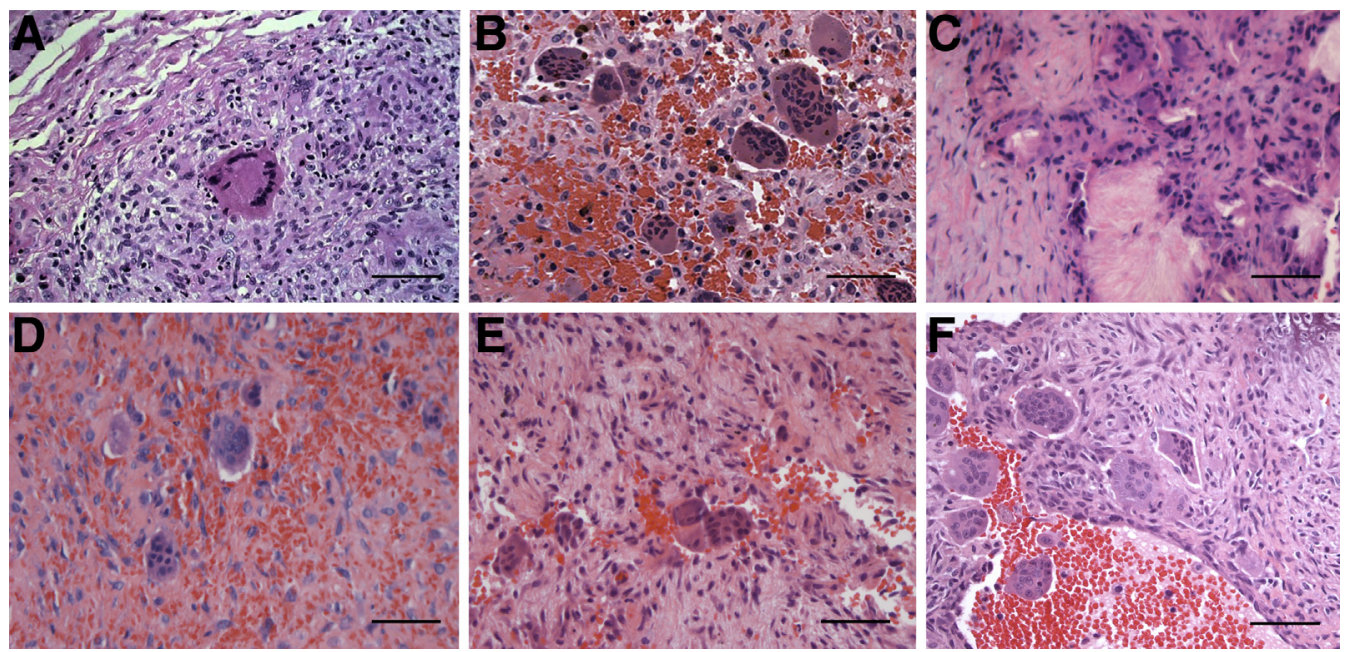

Figure 1 Multinucleated giant cells in pathologic lesions (hematoxylin and eosin staining). A: Chronic tuberculosis, buccal mucosa. B: Central giant cell granuloma, posterior mandible. C: Foreign body giant cell reaction, gingival tissue. D: Brown tumor of hyperparathyroidism, mandible. E: Cherubism, reparative stage, posterior mandible. F: Aneurysmal bone cyst, mandibular condylar head. Scale bars $=100 \mu \mathrm{m}(\mathbf{A}-\mathbf{F})$. Original magnification, $\times 20(\mathbf{A}-\mathbf{F})$. 
Table 1 MGCs in Pathologic Entities

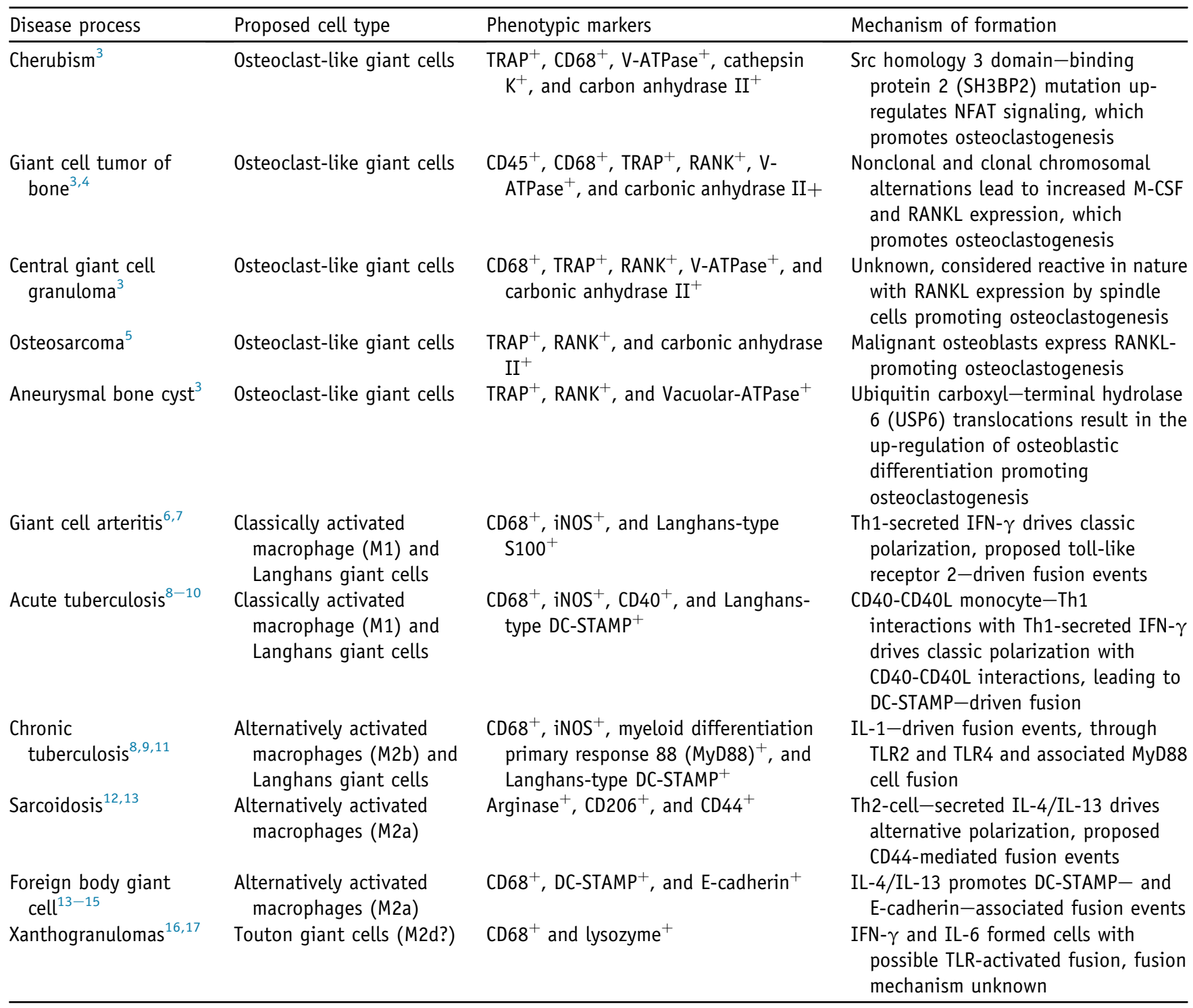

CD40L, CD40 ligand; DC-STAMP, dendritic cell-specific transmembrane protein; IFN- $\gamma$, interferon- $\gamma$; iNOS, inducible nitric oxide synthase; M-CSF, macrophage colony-stimulating factor; MGC, multinucleated giant cell; NFAT, nuclear factor of activated T cells; RANK, receptor activator of NF- $K B$; RANKL, RANK ligand; Th1, type 1 helper T cell; TLR, toll-like receptor; TRAP, tartrate-resistant alkaline phosphatase.

swelling of the faces of young children. ${ }^{22}$ The characteristic mutation of Src homology 3 domain-binding protein 2, which is an activator of nuclear factor of activated $\mathrm{T}$ cells (NFAT), leads to gain of function to promote NFAT signaling, thereby enhancing osteoclastogenesis. ${ }^{23}$ The brown tumor of hyperparathyroidism can mimic the giant cell tumor and arises secondary to hyperparathyroidism from parathyroid neoplasms or end-stage renal disease. Parathyroid hormone secretion leads to increased recruitment of monocytic precursors and RANKL-induced osteoclastogenesis. $^{24}$ For clinical management, endocrine abnormalities should be ruled out in individuals with OCLGC-rich lesions by analysis of calcium, phosphate, and parathyroid hormone levels. ${ }^{25}$ Histologically, both lesions contain OCLGCs and can resemble the giant cell tumor of bone and the central giant cell granuloma (CGCG; Central Giant Cell Granuloma). The MGCs of cherubism and brown tumor express osteoclastic markers, suggesting that these cells are involved in bone resorption.

\section{Central Giant Cell Granuloma}

The CGCG is an MGC-rich lesion with a poorly understood etiology that is found predominantly in the maxillae of young individuals. The CGCG was previously thought to be a reparative granuloma of jawbones due to its less aggressive behavior from giant cell tumors. ${ }^{3}$ Generally, CGCGs are histologically indistinguishable from giant cell tumors and peripheral CGCG variants; they are considered inflammatory lesions and commonly occur on the gingiva. ${ }^{26}$ Some CGCGs exhibit rapid growth and recurrence, 
suggesting a potential neoplastic origin. In CGCGs, spindleshaped mononuclear cells can secrete RANKL, which promotes the formation of MGCs with an osteoclast phenotype (Table 1). ${ }^{3}$

CGCGs were previously considered reparative or reactive in response to intrabony hemorrhage or inflammation; however, new molecular phenotyping suggests a neoplastic origin. ${ }^{27}$ Comprehensive genomic analysis has revealed mutations in BRAF, KRAS, HRAS, guanine nucleotidebinding protein $\mathrm{G}(\mathrm{S})$ subunit $(G N A S)$, microphthalmiaassociated transcription factor (MITF), and platelet-derived growth factor receptor B in CGCGs. The first five of these genes are known drivers in human neoplasms. Although it is not known whether these mutations result in the formation of MGCs, mutations of $B R A F$ and $K R A S$ are associated with Noonan syndrome, which manifests as bilateral CGCG-like lesions. ${ }^{28}$ Mutations of HRAS are associated with recurrent malignant giant cell tumors of bone. Mutations of MITF are associated with dysfunction in osteoclastogenesis through the RANKL-signaling pathway. ${ }^{29,30}$ As these cells exhibit an osteoclast phenotype, the MGCs of CGCGs likely resorb bone and promote lesion progression because even the peripheral variant of CGCGs can exhibit pathologic bone resorption.

\section{Lesions Containing Classically Activated Giant Cells}

Macrophages differentiate into two main subtypes (classically and alternatively activated) that are characterized by discrete metabolic activities and phenotypic markers. In a general sense, classically activated macrophages are associated with acute inflammatory responses, whereas alternatively activated macrophages are associated with resolving inflammatory lesions. In the context of the lesions described in Acute Tuberculosis, classically activated MGCs secrete several effector molecules, including nitric oxide (generated by inducible nitric oxide synthase), which promotes the inflammatory process. ${ }^{31}$

\section{Acute Tuberculosis}

The classic example of giant cell formation in response to microbial challenges is the granuloma caused by Мycobacterium tuberculosis, which is similar in appearance to the lesions of aspergillosis and leprosy. Dendritic cells signal T-helper-1 cells to promote secretion of interferon- $\gamma$ $(\mathrm{IFN}-\gamma)$ in response to antigen presentation. ${ }^{31} \mathrm{IFN}-\gamma$ then promotes activation and recruitment of macrophages to enable these avidly phagocytic cells to engulf and destroy invading organisms. The hallmark feature of tuberculosis is the presence of granulomas, which are collections of mononuclear epithelioid histiocytes organized into a ball-like structure surrounded by a ring of T-helper lymphocytes. Secretion of granulocyte-macrophage colonystimulating factor, IFN- $\gamma$, and IL-3 by helper T cells recruits macrophages and promotes epithelioid changes. ${ }^{32} \mathrm{~T}$ cell-induced secretion of IFN- $\gamma$ leads to enhanced expression of dendritic cell-specific transmembrane protein (DC-STAMP), which promotes the fusion of macrophages and the formation of Langhans giant cells. ${ }^{10}$ Furthermore, macrophages infected with Mycobacterium tuberculosis exhibit increased CD40 and CD57 expression. ${ }^{33}$ Inhibition of either CD40 or CD57 abrogates Langhans giant cell formation, which underlines the significance in MGC formation in tuberculosis. ${ }^{10}$

An important protein expressed by MGCs during the formation of granulomas is E-cadherin, an intercellular adhesion molecule that is associated with mesenchymal-toepithelial transition in granulomatous inflammation in tuberculosis. ${ }^{9}$ Increased expression of E-cadherin promotes the adhesion of adjacent macrophages, whereas inhibition of E-cadherin function blocks granuloma formation. Currently, it is not known whether the intercellular adhesion function of E-cadherin is directly linked to its apparent central role in the development of granulomas. In tuberculosis, Langhans giant cells are thought to restrict the spread of mycobacteria along with granulomas. ${ }^{9}$ The formation of granulomas, however, does not eliminate the causative organism, a situation that enables the development of chronic infections in which MGCs are abundant.

\section{Giant Cell Arteritis}

Giant cell arteritis, an ischemic condition in which intimal hyperplasia and luminal obstruction occur along with MGCs, also appears to be an acute inflammatory response, like some cases of tuberculosis (Table 1). ${ }^{6}$ In these lesions, MGCs may be a response to a microbial antigen or autoantigen, and these cells are associated with expression of matrix metalloproteinase-9, which can promote the vascular destruction seen in this disease. ${ }^{7}$

\section{Lesions Containing Alternatively Activated Type Giant Cells}

On the basis of their activation and protein expression profiles, the MGCs described in Chronic Tuberculosis and Sarcoidosis and Foreign Body Granulomas and Xanthomas are thought to be derived from alternatively activated macrophages. The MGCs formed from antiinflammatory macrophage precursors are avidly phagocytic, suggesting that these cells are associated with immune-mediated removal of exogenous materials or organisms. ${ }^{34}$ If these materials are not phagocytosed or degraded, MGCs expand and persist within affected tissues. Notably, the functional role(s) of MGCs in these lesions has not been definitively demonstrated.

\section{Chronic Tuberculosis and Sarcoidosis}

When the initial immune response to $M$. tuberculosis infection is not resolved, IL-1 $\beta$ expression is enhanced, which drives IL-10 expression by tuberculosis-infected macrophages. ${ }^{35}$ This process promotes the formation of macrophages with an alternatively activated expression 
repertoire. These cells may contribute to the formation of MGCs in tuberculosis lesions, but this mechanism has not been rigorously defined. Furthermore, IL-10 stimulation decreases maturation of the phagosome, blocking phagosome-lysosomal binding and enabling survival and growth of the mycobacteria inside macrophages, which contributes to the chronicity of tuberculosis infections. Notably, toll-like receptors (TLRs) 2 and 4, expressed by macrophages, are associated with the formation of tuberculoid MGCs. ${ }^{36}$

Similar to chronic tuberculosis infections, sarcoidosis lesions contain granulomas populated by MGCs with enhanced arginase activity. ${ }^{12}$ In granulomas of sarcoidosis, T-helper- 2 cells secrete IL-4 and IL-13, which, in turn, drive alternative differentiation of macrophages in response to poorly defined antigens or autoantigens. ${ }^{13}$ The formation of MGCs in these lesions is possibly related to E-cadherin, which is expressed by mononucleated and multinucleated macrophages and is associated with their epithelioid transition into granulomas. CD44 and CCR5 are also involved in homotypic fusion events in the formation of the MGCs of sarcoidosis. Patients who are affected by sarcoidosis have monocytes and macrophages with higher levels of purinergic receptor $\mathrm{P} 2 \mathrm{X} 7$; this receptor is a pharmacologic target for preventing the formation of MGCs and is used in the clinical management of sarcoidosis. ${ }^{37}$ More in-depth insight into global, receptor-specific expression in MGC precursor cells could suggest new targets for therapeutic development.

\section{Foreign Body Granulomas and Xanthogranulomas}

Foreign body giant cells (FBGCs) form when the immune system is exposed to foreign material or to organisms that it cannot phagocytose or degrade. The surface chemistry and topology of foreign materials contribute to activation of cell adhesion molecules, especially $\beta$-integrins. This process leads to the secretion of IL-4 and IL-13, similar to sarcoidosis. ${ }^{38}$ IL-4-induced fusion of macrophages into MGCs depends on $\beta 1$ integrins for cell spreading and intercellular adhesion, whereas $\beta 2$ integrins are required for initial cell attachment to the foreign body. IL-4 promotes the fusion of inflammation-resolving macrophages to form large FBGCs. In turn, FBGCs express CD68 and the major histocompatibility complex class II molecule, human leukocyte antigen $\mathrm{D}$, which enables antigen presentation to T-helper cells and promotes the involvement of adaptive immune recognition systems. ${ }^{20}$ E-cadherin, a prominent intercellular adhesion molecule, is also up-regulated in the foreign body response, similar to sarcoidosis. The expression of E-cadherin may explain why poorly developed granulomas are observed in close proximity to foreign materials. ${ }^{13}$ Similarly to osteoclasts and Langhans giant cells, FBGCs also express DC-STAMP, which complicates cell identification despite the different pathogenesis of these lesions.

Xanthogranulomas contain Touton-type giant cells, a variation of the FBGC, that arise from the fusion of foam cells. ${ }^{17}$ The formation of foam cells, which are macrophages with lipid-filled cytoplasm, is associated with IFN- $\gamma$ and lipopolysaccharide (LPS), suggesting these cells are a form of a proinflammatory macrophage. However, IL-6, which is associated with the formation of inflammation-resolving macrophages, is also linked to foam cell formation. ${ }^{39}$ LPS may promote foam cell formation through activation of TLRs. Although LPS promotes proinflammatory activation of macrophages, TLR-associated cell fusion mainly involves anti-inflammatory macrophages. Therefore, although they exhibit some features of proinflammatory macrophages, it now seems that Touton-type giant cells of xanthogranulomas arise from the fusion of inflammationresolving macrophages. This notion is rationalized by their reparative behavior in the removal of extracellular lipids and activation by IL-6, but the detailed mechanisms are not fully defined. ${ }^{40}$

\section{Multinucleated Giant Cell Subtypes and Their Formation}

There are several different types of MGCs; the most intensively studied of these cells is the osteoclast, a cell type that provides considerable insight into the mechanisms that regulate fusion of precursor cells into MGCs.

\section{0steoclasts}

Osteoclasts are MGCs specialized in the removal of bone matrix and mineral. These cells exhibit apically located nuclei and lysosome fusion with the basal cell membrane and ruffled border during periods of active bone resorption. ${ }^{41}$ Osteoclasts and macrophages express CD45 (the common leukocyte marker) and the pan-macrophage markers CD68 and CD14. ${ }^{42}$ During osteoclast differentiation, committed osteoclasts may cease expression of CD14, a coreceptor for bacterial LPSs. ${ }^{20}$ The vitronectin receptor (CD51 or $\alpha v \beta 3$ integrin), which is also a marker for OCLGCs, enables cell attachment to bone matrix proteins. Tartrate-resistant alkaline phosphatase (TRAP) catalyzes phosphate ester hydrolysis and is highly expressed by osteoclasts. Although TRAP is a well-recognized osteoclast marker, the 5a TRAP isoform may also be expressed by macrophages, which may indicate the activation of these cells in response to inflammation and the production of reactive oxygen species. ${ }^{43}$ In lesions, such as foreign body granulomas and tuberculosis, MGCs are TRAP positive, indicating that, unless specific isoforms are examined, TRAP is not a reliable marker for the differentiation of different MGC subtypes. ${ }^{44}$

\section{Other MGCs}

Although the systems that regulate the fusion of osteoclasts have been examined in detail, other types of MGCs 
(FBGCs, Langhans cells, and Touton giant cells) are formed through different mechanisms.

\section{Foreign Body Giant Cells}

These cells are spatially associated with introduced foreign materials and may exhibit up to 200 nuclei dispersed throughout the cytoplasm. Their formation is mediated, in part, by IL-4 and IL-13. ${ }^{32,45}$ Arginase-1 is overexpressed by mouse monocytes treated with IL-4, consistent with the notion that inflammation-resolving macrophages may fuse to form FBGCs. Furthermore, IL-4 inhibits certain proinflammatory activators and increases expression of CD206 (a mannose receptor), which is important for fusion events. ${ }^{46}$ E-cadherin may also contribute to cell fusion as inhibition of the function of E-cadherin prevents the formation of FBGCs. ${ }^{47}$

\section{Langhans Giant Cells}

Langhans giant cells exhibit peripherally located nuclei (up to 20 nuclei per cell) that surround the Golgi apparatus in a characteristic, horseshoe shape. Ultrastructural studies of these cells show lysosomes that are evenly distributed throughout the cytoplasm. Langhans giant cells are associated with granulomas generated in response to microbial infections, and they are thought to be derived from proinflammatory macrophages as a result of stimulation by granulocyte-macrophage colony-stimulating factor, IFN- $\gamma$, IL-3, and tumor necrosis factor (TNF)- $\alpha .{ }^{32}$ Inhibition of the intercellular adhesion receptor DC-STAMP decreases fusion events, whereas CD40 blockade completely stops the formation of these cells. Therefore, DC-STAMP and CD40 are likely crucial for Langhans giant cell formation, although this notion has not been directly tested. ${ }^{10}$

\section{Touton Giant Cells}

Touton giant cells exhibit multiple, clustered nuclei that are surrounded by a foamy cytoplasm composed of accumulated lipids. When stimulated by macrophage colonystimulating factor, IFN- $\gamma$, or IL-6, monocytes fuse and form MGCs. Touton giant cells are thought to be derived from inflammation-resolving macrophages because of their reparative behavior and IL-6-mediated activation. ${ }^{40}$ The fusion molecules associated with Touton giant cell formation are not well characterized but appear to be associated with activation of TLRs. ${ }^{39}$

\section{Monocyte, Osteoclast, and Macrophage Differentiation}

As described in Multinucleated Giant Cells in Pathology, which discusses the more prevalent inflammatory lesions that contain MGCs, the formation of these cells involves the fusion of monocytic cells, which, in turn, require a priori priming into activated macrophages. An in-depth understanding of the differentiation of monocyte precursor cells into MGCs is crucial for the development of diagnostic markers and for the identification of potential therapeutic targets.

\section{Monocyte Differentiation}

The granulocytic progeny of hematopoietic stem cells differentiate into monocytes and then into the macrophages of the mononuclear phagocyte system. These macrophages, as well as osteoclast precursors, fuse to form MGCs and bone-resorbing multinucleated osteoclasts. Circulating monocytes exist as two populations: patrolling and inflammatory monocytes. ${ }^{48}$ Patrolling monocytes are identified as CX3 chemokine receptor $1(\mathrm{CX} 3 \mathrm{CR} 1)^{\mathrm{high}} / \mathrm{CD} 14^{\mathrm{dim}} / \mathrm{CD} 16^{+}$ in humans and CX3CR $1^{\text {high }} /$ lymphocyte antigen 6 complex $\mathrm{C}(\mathrm{Ly} 6 \mathrm{C})^{-}$in mice. Inflammatory monocytes exhibit $\mathrm{CCR} 22^{\text {high }} / \mathrm{CD} 14^{\text {high }} / \mathrm{CD} 16^{-}$profiles in humans and $\mathrm{CCR} 2^{\text {high }} / \mathrm{Ly} 6 \mathrm{C}^{+}$in mice. Human $\mathrm{CD} 16^{+} / \mathrm{CD} 14^{+}$cells are designated as intermediate inflammatory monocytes. ${ }^{49}$ Patrolling monocytes survey the endothelium and can differentiate into dendritic cells. Inflammatory monocytes, which are the most likely precursor cells for MGCs, are recruited by chemokines that include chemokine (C-C motif) ligand 2 , the ligand for CCR $2 .{ }^{50}$ On entry into peripheral tissues, monocytes differentiate into macrophages or preosteoclasts. The knowledge that circulating inflammatory monocytes are the most likely source of pathologic MGCs is important as insights associated with the differentiation repertoire of these cells may suggest new therapeutic approaches to target recurrent lesions that contain MGCs. Notably, the biology of MGC formation is complicated by the observation that embryonic resident tissue macrophages can also provide a source of precursor cells for macrophages and MGCs. ${ }^{51}$

\section{Osteoclastogenesis}

As discussed in Osteoclasts, osteoclasts provide useful models for definition of the mechanisms that regulate fusion of monocyte precursor cells to form MGCs. Osteoclasts form by the fusion of preosteoclasts, which differentiate from monocytes. The fusion events that lead to osteoclast formation are regulated by a large cadre of cytokines. Monocytes are activated by macrophage colony-stimulating factor-1, which stimulates expression of RANK on the cell surface. RANKL, which is expressed by osteoblasts, stromal cells, and $\mathrm{T}$ cells, promotes the fusion of preosteoclasts. ${ }^{52}$ Osteoprotegerin helps to regulate osteoclastogenesis by acting as a decoy receptor for RANKL. In turn, RANKL promotes osteoclast formation by activating c-Jun N-terminal kinase and NFAT. ${ }^{23,53}$ Although RANKL or RANKdeficient animals cannot generate osteoclasts, TNF- $\alpha$ and LPS (with peptidoglycans) can promote macrophage fusion and osteoclast formation. ${ }^{54}$ These cytokines activate c-Jun $\mathrm{N}$-terminal kinase and NF- $\kappa \mathrm{B}$ signaling pathways in the formation of RANKL-independent osteoclasts. The findings 
that the same signaling pathways for osteoclastogenesis are activated by inflammatory mechanisms indicate why osteoclasts are associated with acute inflammation; however, in addition, IL-1 $\beta$, which was initially described as an osteoclast-activating factor, also promotes multinucleation in monocytes. As mentioned in Osteoclasts, osteoclasts express TRAP, cathepsin K, and DC-STAMP. ${ }^{55}$ IL-1 $\beta$ induces the fusion of monocytes, a process that involves the TNF receptor-associated factor 6 , which, in turn, interacts with IL-1 receptor-associated kinase to promote osteoclast activation and to stimulate fusion involving cytoskeletal rearrangement. ${ }^{56}$ Furthermore, IL-1 acts indirectly on osteoblasts to increase expression of prostaglandin E2 and RANKL, which increase osteoclast differentiation. ${ }^{57}$ These well-known processes in osteoclasts have not yet been definitively elucidated in the MGCs that form in the lesions of macrophage origin.

\section{Macrophage Differentiation}

Macrophages, which are derived from monocytes, are heterogeneous populations of cells, as shown by their broad gene expression profiles and by the molecules that they phagocytose and secrete. ${ }^{58}$ Similarly, MGCs, which are formed by the fusion of monocytes or macrophages, exhibit an array of singular features. Macrophage differentiation has been associated with a broad spectrum of activation states, which were initially classified on the basis of the notion of classically activated macrophages (M1 cells; considered as proinflammatory) and alternatively activated macrophages (M2 cells; considered as inflammation resolving). ${ }^{59}$ More recent insights show that the M1/M2 classification system only partially represents the spectrum of macrophage phenotypes. Conceivably, as more subtypes are characterized, the protein expression repertoires and functional profiles of cells will motivate that development of a more comprehensive classification system. Nevertheless, macrophage populations that exhibit various proinflammatory and anti-inflammatory properties contribute to the formation of the MGCs that comprise non-OCLGCcontaining lesions.

\section{Classically Activated Macrophages}

M1 macrophages were originally considered to be generated from monocytic precursor cells after exposure to IFN$\gamma$, TNF, and damage- and pathogen-associated molecular patterns. $^{60}$ Damage-associated molecular patterns are produced by the host, and their pathogen-derived counterparts, pathogen-associated molecular patterns, can include bacterial products, such as LPSs, that promote a proinflammatory activation. These cytokines include those expressed in giant cell arteritis and acute tuberculosis. M1s are highly phagocytic cells that remove pathogens and debris and exhibit a shift from arginine-1 metabolism to nitric oxide synthase, which facilitates killing of pathogens. Their phenotype is characterized by an inducible nitric oxide synthase-positive/CXCL1 $11^{+} / \mathrm{IL}-12^{\text {high }} / \mathrm{IL}$ $23^{\text {high }} / \mathrm{IL}-10^{\text {low }}$ profile. ${ }^{61}$ Furthermore, M1 cells secrete other cytokines and chemokines (eg, TNF- $\alpha$, IL- $1 \beta$, and IL-6) that activate other macrophages and perpetuate the proinflammatory immune response. In the context of MGC formation, there are rich opportunities for definition of MGC subtypes through examination of the expression repertoire of molecules associated with the so-called M1 macrophages.

\section{Alternatively Activated Macrophages}

Alternatively activated M2s, the reparatory macrophages, produce ornithines through the arginase pathway, which are associated with enhanced cell proliferation, healing, and suppressed T-cell responses. ${ }^{62}$ M2 macrophages are also avidly phagocytic and produce extracellular matrix molecules, chemotactic factors, and angiogenic factors. Alternatively activated macrophages are subdivided into four types (a to d) based on their activation stimuli; however, evolution of the classification system may result in new subdivisions based on metabolic profiling. M2a macrophages are generated by exposure to IL- 4 or IL-13, as are the MGCs seen in foreign body reactions. These cells are known to be found in inflammatory zone 1 (FIZZ1) ${ }^{+}$/arginase $1(\operatorname{Arg} 1)^{+} / \mathrm{IL}-12^{\text {low }} / \mathrm{IL}-23^{\text {low }}$ and secrete $\mathrm{IL}-10$ on Fc receptor- $\gamma$ activation. ${ }^{61}$ M2a macrophages attenuate M1associated inflammation; contribute to extracellular matrix synthesis, encapsulation of foreign bodies, and fibrosis; and inhibit $\mathrm{T}$ cells. ${ }^{63} \mathrm{M} 2 \mathrm{~b}$ macrophages (type 2) are generated after exposure to IL-1; are activators of TLRs and immune complexes, such as those seen in chronic tuberculosis; and show CD $80^{\text {high }} / \mathrm{CD} 14^{\text {high }} /$ human leukocyte antigen-DR ${ }^{\text {low }} /$ $\mathrm{IL}-12^{\text {low }} / \mathrm{IL}-23^{\text {low }}$ expression. ${ }^{8,11}$ M2b macrophages upregulate antigen presentation and promote T-helper- 2 responses. M2c cells arise in response to IL-10, transforming growth factor- $\beta$, or glucocorticoids; they are referred to as deactivated macrophages because of their expression of an M2 profile after activation in culture. ${ }^{64}$ These cells induce T-regulatory cells to aid in their anti-inflammatory activities. M2d cells are formed in response to IL-6 and adenosine, and they are associated with angiogenesis and tissue repair. ${ }^{65}$ The determination of the proportion and relative abundance of M1 and M2 markers of MGCs that populate MGCcontaining lesions would seem to be a reasonable starting point for advancing our understanding of their ontogeny.

\section{Cell Fusion in MGC Formation}

Identification of the molecules involved in the formation of MGCs from various monocyte- and macrophage-derived precursors could help to define the role of these cells in MGC-associated diseases, elucidate their pathogeneses, and serve as potential pharmacologic targets. Indeed, the molecules and processes involved in the formation of MGCs are just now being defined. It is generally recognized that for all 


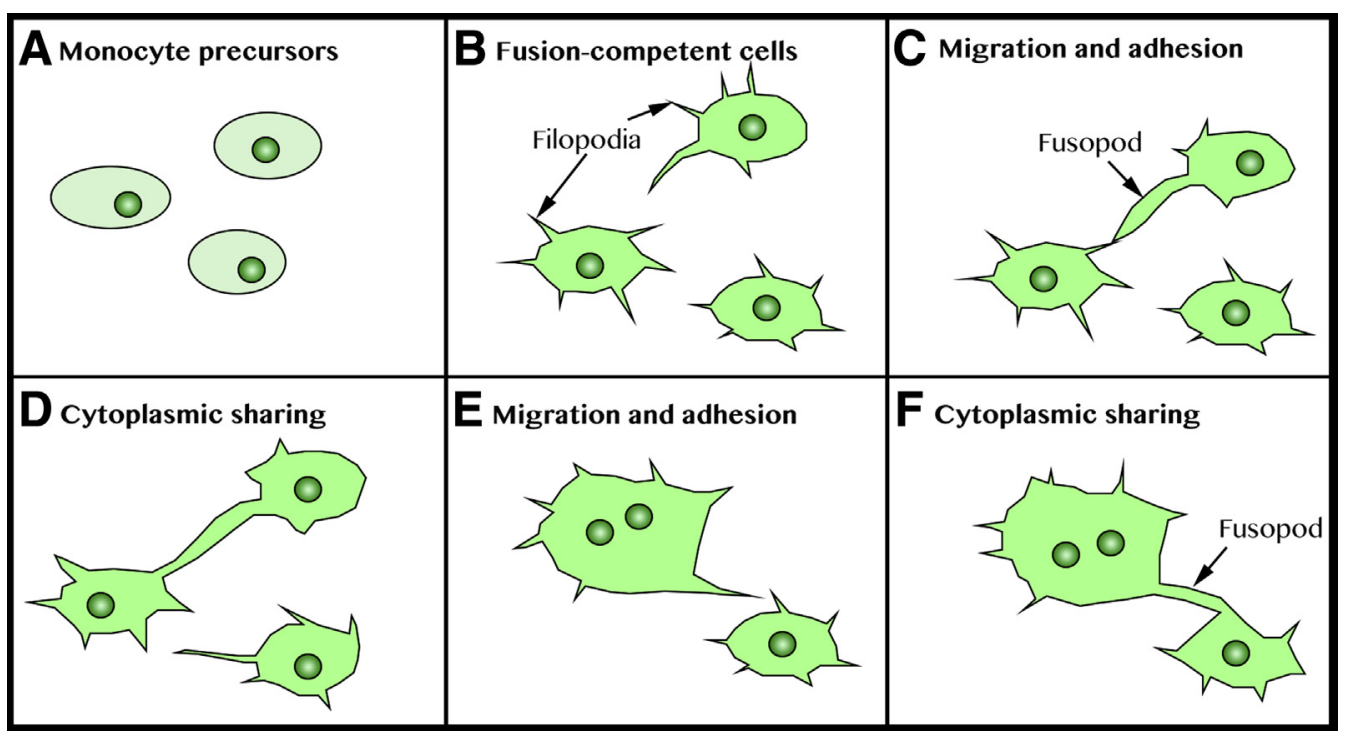

Figure 2 A and B: Formation of multinucleated giant cells (MGCs) begins with monocyte precursor cells (A) that obtain fusion competence through the presence of profusogenic cytokines and then extend actin-rich filopodial projections (B). C: The cells undergo migration toward one another, and adhesion occurs via filopodial projections or fusopods; at opposing sites, fusogens enable approximation of plasma membranes. D: Removal of the intervening membranes allows for cytoplasmic sharing and the formation of a binucleated cell. $\mathbf{E}$ and $\mathbf{F}$ : Cells migrate and adhere again (E), followed by cytoplasmic sharing to form an MGC (F).

cell types that undergo fusion (eg, myoblasts, trophoblasts, and monocytes), three discrete stages of fusion are involved: the development of fusion competency; migration; followed by intercellular adhesion and cytoplasmic sharing (Figure 2). ${ }^{66}$ Fusion competency indicates that the cells express the appropriate proteins and exhibit the required function to undergo fusion. This process occurs when potentially fusogenic cells migrate toward one another, approximate their plasma membranes, and then lose the intervening membrane bilayers to enable cytoplasmic sharing. In this section, we discuss in detail the first two stages of MGC fusion as they relate to the formation of MGCs in pathologic lesions.

\section{Fusion Competence}

For fusion to occur, cells must become fusion competent, which indicates that they must express the adhesion molecules (fusogens) that will enable cell membrane approximation and the expression of the machinery required for fusion. Fusogens lower the energy barrier between lipid bilayers, which allows cells to be in close proximity despite charge repulsion. Fusogens are delivered via membrane lipid rafts to the approximating plasma membranes. The membranes also recruit other adhesion molecules to the adhesion site because of the assembly of subcortical actin filaments and filament flow in the plan of the cortex. ${ }^{67}$ The fusion molecules important in the formation of each type of MGC are depicted in Figure 3. The intercellular adhesion machinery in the fusion process is linked to the generation of signals that bring opposing membranes toward one another. Here, we consider some of the best-described intercellular adhesion molecules that are involved in fusion.

\section{DC-STAMP}

DC-STAMP is a transmembrane protein that is critical for the formation of multinucleated osteoclasts. When DC-STAMP is deleted in mice, multinucleation is blocked. ${ }^{14}$ Although the ligand of DC-STAMP is not known, it may be a chemokine, based on the similarity of the structure of DC-STAMP with other chemokine receptors. RANK promotes binding of c-Fos and NFATc1 to the $D C$-STAMP promoter. ${ }^{68}$ Accordingly, in IL-4-induced FBGC formation, c-Fos, NFATc1, PU.1, and NF- $\kappa \beta$ regulate DC-STAMP expression. Activation of DC-STAMP leads to NFAT and calcium signaling, which are important for osteoclastogenesis. ${ }^{69}$

DC-STAMP contains an immunoreceptor tyrosine-based inhibition motif in its cytosolic domains that is essential for NFAT nuclear translocation and cell fusion. ${ }^{69}$ Immunoreceptor tyrosine-based inhibition motifs recruit tyrosine phosphatases (eg, Src homology 2 domain tyrosine phosphatase), which regulate signaling of immunoreceptoractivating motifs to activate downstream signaling. Although DC-STAMP is important in RANKL-mediated osteoclastogenesis, it is not required for the formation of FBGCs involving the fusion of M2a cells. ${ }^{68}$

\section{Cadherins}

Cadherins are transmembrane adhesion receptors, one of which (E-cadherin) is important for homotypic fusion in cells of monocytic origin. ${ }^{47}$ IL-4 and IL-13 increase surface expression of E-cadherin through a STAT6-dependent signaling pathway. ${ }^{70}$ Although the E-cadherin promoter 


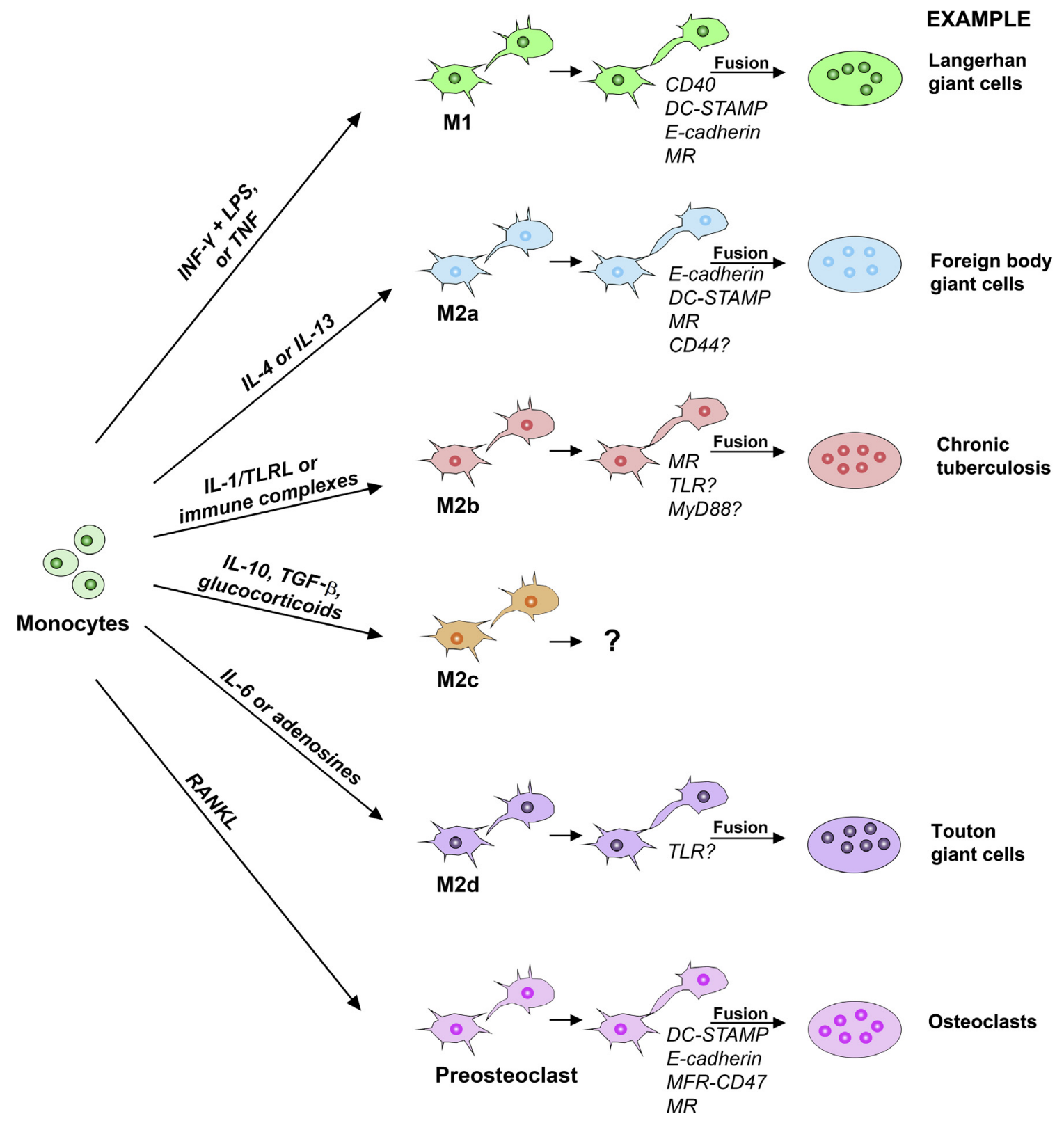

Figure 3 Formation of multinucleated giant cells (MGCs) from various types of monocyte differentiation. Activation of monocytes by various cytokines leads to the differentiation of macrophages. Actin-rich cellular extension processes, filopodia, approximate cells with one another; and the proposed fusogens expressed by these cells enable fusion events to form the various MGCs. DC-STAMP, dendritic cell-specific transmembrane protein; IFN- $\gamma$, interferon- $\gamma$; LPS, lipopolysaccharide; MFR, macrophage fusion receptor; MR, mannose receptor; MyD88, myeloid differentiation primary response 88; RANKL, receptor activator of NF- $\mathrm{B}$ ligand; TGF- $\beta$, transforming growth factor- $\beta$; TLR, toll-like receptor; TLRL, TLR ligand; TNF, tumor necrosis factor.

does not contain a STAT6 binding site, polyamines produced in M2a macrophages, in response to IL-4 up-regulation of arginase metabolism, are crucial cofactors for the induction of E-cadherin expression. ${ }^{70}$ Although the recruitment of E-cadherins (along with $\beta$-catenin and p120catenin) enables homotypic adhesive interactions, reduced expression of E-cadherin does not inhibit MGC formation entirely. ${ }^{70}$ IL-4-naïve cells are able to undergo fusion events with IL-4-treated cells, indicating that donor and acceptor cell adhesion events occur independently of homotypic binding involving E-cadherin.
In cultured cells, E-cadherin is a ligand for killer cell lectin-like receptor subfamily $\mathrm{G}$ member $1{ }^{71}$ The killer cell lectin-like receptor subfamily $\mathrm{G}$ member 1 also contains an immunoreceptor tyrosine-based inhibition motif cytosolic component that is similar in structure to DC-STAMP. However, binding of E-cadherin to monocytes leads to reduction of secretion of inflammatory cytokines, indicating a modulatory role of this adhesion receptor. Osteoclasts also use E-cadherin in fusion processes: blockade of E-cadherin in RANKL-treated cells diminishes multinucleation in osteoclast formation. ${ }^{72}$ Inhibition of E-cadherin also retards 
the expression of TRAP, cathepsin K, DC-STAMP, and NFATc1, but this effect is evidently not crucial for osteoclastogenesis. Accordingly, E-cadherin may be associated with the induction of genes in osteoclasts that promote cell motility and fusion competency.

\section{Mannose Receptor}

A critical regulator of adhesion in osteoclasts and FBGCs is CD206 (a mannose receptor). ${ }^{73} \mathrm{CD} 206$ is a lectin receptor expressed on cells that detects microorganisms expressing mannose oligosaccharides. The mechanism by which the mannose receptor promotes cell fusion in MGCs is unknown but may involve collagen clearance and enhanced cell migration through the extracellular matrix to increase the likelihood of cell approximation. ${ }^{74}$

The expression of CD206 is enhanced by IL-4 and IL-13, whereas inhibition of CD206 decreases IL-4-induced MGC formation. ${ }^{75}$ However, the expression of CD206 is not required for MGC formation, indicating that other fusogens may play more central roles in critical fusion events. Osteoclasts and their precursors also express CD206, but inhibition of CD206 function only partially attenuates the formation of TRAP-positive osteoclasts. In the context of the formation of MGCs, CD206 can recognize several pathogens, notably M. tuberculosis. In these lesions, CD206 mediates macrophage adhesion and MGC formation. ${ }^{75}$ The development of CD206-directed therapeutics is now underway for treatment of tuberculosis through improved uptake of drugs and the targeting of medication-resistant granulomas that form. ${ }^{76} \mathrm{~A}$ potential shortcoming of this approach is that CD206 is expressed by MGCs in several different pathologic processes, including osteoclasts, which may inadvertently impact normal physiological processes.

\section{MFR and CD47}

The macrophage fusion receptor (MFR; alias signalregulatory protein $\alpha$ ) belongs to the Ig superfamily of proteins and interacts both homotypically and heterotypically with other members of the Ig superfamily, integrins and cadherins. ${ }^{77}$ MFR is a transmembrane adhesion protein expressed on the plasma membrane of macrophages and dendritic cells. ${ }^{78}$ Its adhesion partner, CD47, is a member of the Ig superfamily. CD47 is expressed ubiquitously and was originally associated with the $\alpha \mathrm{v} \beta 3$ integrin. ${ }^{79}$ Inhibition of the MFR-CD47 interaction reduces osteoclast number in vivo, ${ }^{80}$ in part by affecting cell fusion. The MFR-CD47 interaction recruits SHP-1 and SHP-2 to phosphorylated immunoreceptor tyrosine-based inhibition motifs, a process that promotes fusion of preosteoclasts through activation of nonmuscle myosin. ${ }^{81}$ CD47 also participates in MGC formation, which has been demonstrated in experiments using CD47 antibody blockade to inhibit macrophage fusion. ${ }^{82}$ One report has indicated that expression of a mutated MFR did not affect osteoclast formation in mice, although the osteoclasts in these animals exhibited increased activity, indicating a possible regulatory role of MFR in cell fusion and osteoclastogenesis. ${ }^{83}$ The MFR-CD47 interaction may facilitate cell-cell fusion through initial approximation and subsequent adhesion of adjacent plasma membranes; a smaller MFR isoform decreases the distance between fusing cell membranes. CD47 also interacts with integrins to encourage chemotaxis and migration. Accordingly, increased CD47 availability in cells with mutant MFR could lead to increased activity of these cells.

\section{Cell Approximation}

In cultured monocytes undergoing fusion, morphologic studies have shown that a larger founder cell seeks out a smaller follower cell for fusion to occur. ${ }^{84}$ In addition to membrane fusion events, these processes centrally involve the assembly of subcortical actin filaments at the cell fusion sites.

\section{Cytoskeletal Regulation of Fusion}

The importance of actin filaments in fusion processes is readily apparent in cells in which inhibition of Ras-related C3 botulism toxin substrate 1 (Rac1), a small GTPase that regulates the actin cytoskeleton, blocks RANKL-mediated fusion. ${ }^{85}$ Inhibition of Rac1 does not affect the phagocytic functions of MGCs. ${ }^{86}$ Rho GTPases, such as Rac, control osteoclast formation by regulating the assembly of filopodia, lamellipodia, and podosomes. ${ }^{87}$ Filopodia, which are cell extensions composed of short bundles of actin filaments, are at the forefront of fusion events. ${ }^{85}$ These cell extensions are associated with chemotactic sensing, the direction of cell migration, and cell attachment to substrates. The filopodia that enable approximation and membrane fusion are termed fusopods. During the formation of FBGC, filopodia contribute to the sharing of cytoplasm between fusing cells. ${ }^{88}$ Other cytoskeletal molecules that affect fusion processes include Rac2, a GTPase that is distinct from Rac1; and filamin $\mathrm{A}$, an actin filament cross-linking protein. ${ }^{89,90}$

\section{Phospholipid Membrane Regulation of Fusion}

Regulation of fusion events is modulated, in part, by molecules embedded in the phospholipid bilayer of fusing cell membranes. Immobilization of phosphatidylethanolamine, a smallheaded phospholipid, prevents the formation of filopodia and, as a result, osteoclastogenesis is inhibited. ${ }^{91}$ Modification of the lipids in the leaflets of the plasma membranes is critical in the early stages of membrane fusion. ${ }^{92}$ Phosphatidylserine is a negatively charged phospholipid located on the cytosolic side of the phospholipid membrane, but it translocates to the outer membrane before fusion. Phosphatidylserine depletes cholesterol, which increases membrane fluidity and promotes the movement of the lipid raft. When phosphatidylserine is masked, IL-4-induced fusion of macrophages is inhibited. ${ }^{92}$

\section{Intercellular Adhesion and Cytoplasmic Sharing}

Before cytoplasmic sharing can occur, the fusogens that endow fusion-competence need to be activated by their 
fusion partner. In this context, once intercellular adhesion has occurred, the purinergic receptor $\mathrm{P} 2 \mathrm{X} 7$ is thought to control phospholipid exposure, which is then recognized by CD36, the scavenger receptor. ${ }^{93} \mathrm{P} 2 \mathrm{X} 7$ is an ATP-gated ion channel that enhances ion permeation during MGC formation as a result of plasma membrane permeabilization. ${ }^{94}$ Partial silencing of P2X7 in Raw264.7 cells leads to decreased gene expression of NFATc1 and cathepsin K, along with reduction of the size and bone-resorbing function of osteoclasts. ${ }^{95}$ Inhibition of $\mathrm{P} 2 \mathrm{X} 7$ reduces the probability of cell fusion events and is thought to be associated with the final stage of cell fusion events, cytoplasmic sharing.

\section{Fusion Models}

On the basis of our lack of knowledge of the molecular determinants of MGC formation in a wide variety of lesions that contain these cells, an important future goal will be to develop robust models that will enable the characterization of the critical molecules that enable fusion to occur. Notably, knockout mouse models of DC-STAMP, OCSTAMP (a variant of DC-STAMP), P2X7 receptor, and CD47 have been used to determine the roles of these proteins in cell fusion in intact animals. ${ }^{14,79,96,97}$ Measurement of the ability of cells to form MGCs in experimental lesions or under experimental conditions in which these potential fusogens are deleted could give insight into how these molecules regulate the formation of specific types of MGCs. In cultured cells, the functional roles of potential fusogenic proteins in the formation of actin-rich filopodial projections has been examined using three-dimensional imaging, which enables high-resolution analysis of fusopod-driven events. ${ }^{85}$ In these approaches, cells are cultured on membranes containing small pores that allow the monitoring of filopodia as they extend through the pores, allowing for the study of the assembly of actin filaments and the impact of specific actin regulatory proteins on cell extension formation. ${ }^{98}$ These methods will help to uncover the mechanistic details of MGC formation.

\section{Applications and Conclusions}

Evidently, there are important gaps in our understanding of MGC formation, including the molecular determinants of cell fusion. Therefore, it is critical to obtain an in-depth understanding of the molecules that promote formation of MGCs and thereby to link specific fusion molecules with discrete, MGC-associated diseases. The identification of these MGC type-specific molecules could significantly advance diagnosis of these diseases and lead to the discovery of new drug targets. Currently, our ability to discriminate MGC variants on histologic criteria alone is challenging and is a major hurdle for further progress. Notably, the discovery of a specific fusion molecule involved in the formation of MGCs led to the discovery of the role of the mannose receptor in the formation of tuberculoid granulomas. ${ }^{76,99}$ This knowledge has been applied to the generation of mannose receptor-targeted therapies, which can penetrate medication-resistant granulomas in the treatment of tuberculosis. Presumably, if these differentially expressed fusogens could be identified, the diagnosis of MGC-containing lesions would be expedited. The application of broad and unbiased proteomic approaches could be used to detect novel fusogenic molecules that are differentially expressed in discrete MGCs. Identification of molecules with membrane surface expression could provide new targets for diagnostics and moleculetargeted therapies.

\section{References}

1. Chambers TJ: Multinucleate giant cells. J Pathol 1978, 126:125-148

2. Schaefer IM, Hornick JL: Diagnostic immunohistochemistry for soft tissue and bone tumors: an update. Adv Anat Pathol 2018, 25: 400-412

3. Liu B, Yu S-F, Li T-J: Multinucleated giant cells in various forms of giant cell containing lesions of the jaws express features of osteoclasts. J Oral Pathol Med 2003, 32:367-375

4. Atkins GJ, Kostakis P, Vincent C, Farrugia AN, Houchins JP, Findlay DM, Evdokiou A, Zannettino AC: RANK expression as a cell surface marker of human osteoclast precursors in peripheral blood, bone marrow, and giant cell tumors of bone. J Bone Miner Res 2006, 21:1339-1340

5. Branstetter D, Rohrbach K, Huang L-Y, Soriano R, Tometsko M, Blake M, Jacob AP, Dougall WC: RANK and RANK ligand expression in primary human osteosarcoma. J Bone Oncol 2015, 4: $59-68$

6. Watanabe R, Goronzy JJ, Berry G, Liao J, Weyand CM: Giant cell arteritis: from pathogenesis to therapeutic management. Curr Treatm Opt Rheumatol 2016, 2:126-137

7. Samson M, Corbera-Bellalta M, Audia S, Planas-Rigol E, Martin L, Cinta Cid M, Bonnotte B: Recent advances in our understanding of giant cell arteritis pathogenesis. Autoimmun Rev 2017, 16:833-844

8. McClean CM, Tobin DM: Macrophage form, function, and phenotype in mycobacterial infection: lessons from tuberculosis and other diseases. Pathog Dis 2016, 64:ftw068

9. Cronan MR, Beerman RW, Rosenberg AF, Saelens JW, Johnson MG, Oehlers SH, Sisk DM, Jurcic Smith KL, Medvitz NA, Miller SE, Trinh LA, Fraser SE, Madden JF, Turner J, Stout JE, Lee S, Tobin DM: Macrophage epithelial reprogramming underlies mycobacterial granuloma formation and promotes infection. Immunity 2016, 45:861-876

10. Sakai H, Okafuji I, Nishikomori R, Abe J, Izawa K, Kambe N, Yasumi T, Nakahata T, Heike T: The CD40-CD40L axis and IFN- $\gamma$ play critical roles in Langhans giant cell formation. Int Immunol 2011, 24:5-15

11. Puissegur MP, Lay G, Gilleron M, Botella L, Nigou J, Marrakchi H, Mari B, Duteyrat JL, Guerardel Y, Kremer L, Barbry P, Puzo G, Altare F: Mycobacterial lipomannan induces granuloma macrophage fusion via a TLR2-dependent, ADAM9- and beta1 integrin-mediated pathway. J Immunol 2007, 178:3161-3169

12. Prokop S, Heppner FL, Goebel HH, Stenzel W: M2 polarized macrophages and giant cells contribute to myofibrosis in neuromuscular sarcoidosis. Am J Pathol 2011, 178:1279-1286

13. Wanat KA, Rosenbach M, Zoiber AF, Zhang PJ, Schaffer A: Ecadherin is expressed by mono- and multinucleated histiocytes in cutaneous sarcoidal and foreign body granulomas. Am J Dermatopathol 2014, 36:651-654 
14. Yagi M, Miyamoto T, Sawatani Y, Iwamoto K, Hosogane N, Fujita N, Morita K, Ninomiya K, Suzuki T, Miyamoto K, Oike Y, Takeya M, Toyama Y, Suda T: DC-STAMP is essential for cell-cell fusion in osteoclasts and foreign body giant cells. J Exp Med 2005, 202:345-351

15. McNally A, Anderson JM: Foreign body-type multinucleated giant cells induced by interleukin-4 express select lymphocyte costimulatory molecules and are phenotypically distinct from osteoclasts and dendritic cells. Exp Mol Pathol 2011, 91:673-681

16. Quinn MT, Schepetkin IA: Role of NADPH oxidase in formation and function of multinucleated giant cells. J Innate Immun 2009, 1: $509-526$

17. Reiss AB, Patel CA, Rahman MM, Chan ES, Hasneen K, Montesinos MC, Trachman JD, Cronstein BN: Interferon-gamma impedes reverse cholesterol transport and promotes foam cell transformation in THP-1 human monocytes/macrophages. Med Sci Monit 2004, 10:420-425

18. Cowan RW, Singh G: Giant cell tumor of bone: a basic science perspective. Bone 2013, 52:238-246

19. Lau AW, Pringle LM, Quick L, Riquelme DN, Ye Y, Oliveira AM, Chou MM: TRE17/ubiquitin-specific protease 6 (USP6) oncogene translocated in aneurysmal bone cyst blocks osteoblastic maturation via an autocrine mechanism, involving bone morphogenetic protein dysregulation. J Biol Chem 2010, 285:37111-37120

20. Maggiani F, Forsyth R, Hogendoorn PC, Krenacs T, Athanasou NA: The immunophenotype of osteoclasts and macrophage polykaryons. J Clin Pathol 2011, 64:701-705

21. Lewin J, Thomas D: Denosumab: a new treatment option for giant cell tumor of bone. Drugs Today 2013, 49:693-700

22. Ueki Y, Tiziani V, Santanna C, Fukai N, Maulik C, Garfinkle J, Ninomiya C, doAmaral C, Peters H, Habal M, Rhee-Morris L, Doss JB, Kreiborg S, Olsen BR, Reichenberger E: Mutations in the gene encoding c-Abl-binding protein SH3BP2 cause cherubism. Nat Genet 2001, 28:125-126

23. Leitman SA, Yin L, Levine MA: SH3BP2 is an activator of NFAT activity and osteoclastogenesis. Biochem Biophys Res Commun 2008, 371:644-648

24. Li $\mathrm{X}$, Qin L, Bergenstock M, Bevelock LM, Novack DV, Partridge NC: Parathyroid hormone stimulates osteoblastic expression of MCP-1 to recruit and increase the fusion of pre/osteoclasts. J Biol Chem 2007, 282:33098-33106

25. Keyser JS, Postma GN: Brown tumor of the mandible. Am J Otolaryngol 1996, 17:407-410

26. Gnepp DR: Lesions of the oral cavity. Diagnostic Surgical Pathology of the Head and Neck, ed 2. Philadelphia, PA: Saunders Elsevier Inc., 2009. pp. 207-208

27. Bezak B, Lehrke H, Elvin J, Gay L, Schembri-Wismayer D, Viozzi C: Comprehensive genomic profiling of central giant cell lesions identifies clinically relevant genomic alterations. J Oral Maxillofac Surg 2017, 75:955-961

28. Tartaglia M, Zampino G, Gelb BD: Noonan syndrome: clinical aspects and molecular pathogenesis. Mol Syndromol 2010, 1:2-26

29. Oda Y, Sakamoto A, Saito T, Matsuda S, Tanaka K, Iwamoto Y, Tsuneyoshi M: Secondary malignant giant-cell tumour of bone: molecular abnormalities of p53 and H-ras gene correlated with malignant transformation. Histopathology 2001, 39:629-637

30. Lu S-Y, Li M, Lin Y-L: Mitf induction by RANKL is critical for osteoclastogenesis. Mol Biol Cell 2010, 21:1763-1771

31. Miranda MS, Breiman A, Allain S, Deknuydt F, Altare F: The tuberculous granuloma: an unsuccessful host defence mechanism providing a safety shelter for the bacteria? Clin Dev Immunol 2012, 2012:139127

32. McNally AK, Anderson JM: Interleukin-4 induces foreign body giant cells from human mono-cytes/macrophages: differential lymphokine regulation of macrophage fusion leads to morphological variants of multinucleated giant cells. Am J Pathol 1995, 147:1487-1499
33. Mihret A: The role of dendritic cells in Mycobacterium tuberculosis infection. Virulence 2012, 3:654-659

34. Milde R, Ritter J, Tennent GA, Loesch A, Martinez FO, Gordon S, Pepys MB, Verschoor A, Helming L: Multinucleated giant cells are specialized for complement-mediated phagocytosis and large target destruction. Cell Rep 2015, 13:1937-1948

35. O'Leary S, O'Sullivan MP, Keane J: IL-10 blocks phagosome maturation in mycobacterium tuberculosis-infected human macrophages. Am J Respir Cell Mol Biol 2011, 45:172-180

36. Wang H, Maeda Y, Fukutomi Y, Makino M: An in vitro model of Mycobacterium leprae induced granuloma formation. BMC Infect Dis 2013, 13:279

37. Okamoto H, Mizuno K, Horio T: Monocyte-derived multinucleated giant cells and sarcoidosis. J Dermatol Sci 2003, 31:119-128

38. McNally AK, Anderson JM: $\beta 1$ and $\beta 2$ integrins mediate adhesion during macrophage fusion and multinucleated foreign body giant cell formation. Am J Pathol 2002, 160:621-630

39. Funk JL, Feingold KR, Moser AH, Grunfeld C: Lipopolysaccharide stimulation of RAW 264.7 macrophages induces lipid accumulation and foam cell formation. Atherosclerosis 1993, 98:67-82

40. Lemaire I, Yang H, Lafont V, Dornand J, Commes T, Cantin MF: Differential effects of macrophage- and granulocyte-macrophage colony-stimulating factors on cytokine gene expression during rat alveolar macrophage differentiation into multinucleated giant cells (MGC): role for IL-6 in type 2 MGC formation. J Immunol 1996, 157:5118-5125

41. Lacombe J, Karsenty G, Ferron M: Regulation of lysosome biogenesis and functions in osteoclasts. Cell Cycle 2013, 12: 2744-2752

42. Athanasou NA, Quinn J: Immunophenotypic differences between osteoclasts and macrophage polykaryons: immunohistological distinction and implications for osteoclast ontogeny and function. J Clin Pathol 1990, 43:997-1004

43. Janckila AJ, Yam LT: Biology and clinical significance of tartrateresistant acid phosphatases: new perspectives on an old enzyme. Calcif Tissue Int 2009, 85:465-483

44. Seo K-J, Yoo C-Y, Im S-Y, Yeo C-D, Jung J-H, Choi H-J, Yoo J-Y: A possible complementary tool for diagnosing tuberculosis: a feasibility test of immunohistochemical markers. Int J Clin Exp Pathol 2015, 8:13900-13910

45. DeFife KM, Jenney CR, Colton E, Anderson JM: Cytoskeletal and adhesive structural polarizations accompany IL-13-induced human macrophage fusion. J Histochem Cytochem 1999, 47:65-74

46. Kurachi T, Morita I, Oki T, Ueki T, Sakaguchi K, Enomoto S, Murota S: Expression on outer membranes of mannose residues, which are involved in osteoclast formation via cellular fusion events. J Biol Chem 1994, 269:17572-17576

47. Moreno JL, Mikhailenko I, Tondravi MM, Keegan AD: IL-4 promotes the formation of multinucleated giant cells from macrophage precursors by a STAT6-dependent, homotypic mechanism: contribution of E-cadherin. J Leukoc Biol 2007, 82:1542-1553

48. Geissmann F, Jung S, Littman DR: Blood monocytes consist of two principal subsets with distinct migratory properties. Immunity 2003 , $19: 71-82$

49. Wong KL, Yeap WH, Tai JJY, Ong SM, Dang TM, Wong SC: The three human monocyte subsets: implications for health and disease. Immunol Res 2012, 53:41-57

50. Shi C, Pamer EG: Monocyte recruitment during infection and inflammation. Nat Rev Immunol 2011, 11:762-774

51. Ginhoux F, Jung S: Monocytes and macrophages: developmental pathways and tissue homeostasis. Nat Rev Immunol 2014, 14:392-404

52. Arai $\mathrm{F}$, Miyamoto $\mathrm{T}$, Ohneda $\mathrm{O}$, Inada $\mathrm{T}$, Sudo $\mathrm{T}$, Brasel $\mathrm{K}$, Miyata T, Anderson DM, Suda T: Commitment and differentiation of osteoclast precursor cells by the sequential expression of c-Fms and receptor activator of nuclear factor kappaB (RANK) receptors. J Exp Med 1999, 190:1741-1754 
53. Xu J, Wu HF, Ang ES, Yip K, Woloszyn M, Zheng MH, Tan RX: NF- $\kappa \mathrm{B}$ modulators in osteolytic bone diseases. Cytokine Growth Factor Rev 2009, 20:7-17

54. Hotokezaka H, Sakai E, Ohara N, Hotokezaka Y, Gonzales C, Matsuo K-I, Fujimura Y, Yoshida N, Nakayama K: Molecular analysis of RANKL-independent cell fusion of osteoclast-like cells induced by TNF-alpha, lipopolysaccharide, or peptidoglycan. J Cell Biochem 2007, 101:122-134

55. Cao Y, Jansen ID, Sprangers S, Stap J, Leenen PJ, Everts V, de Vries TJ: IL-1 $\beta$ differently stimulates proliferation and multinucleation of distinct mouse bone marrow osteoclast precursor subsets. J Leukoc Biol 2016, 100:513-523

56. Nakamura I, Kadono Y, Takayanagi H, Jimi E, Miyazaki T, Oda H, Nakamura K, Tanaka S, Rodan GA, Duong LT: IL-1 regulates cytoskeletal organization in osteoclasts via TNF receptor-associated factor 6/c-Src complex. J Immunol 2002, 168:5103-5109

57. Akatsu T, Takahashi N, Udagawa N, Imamura K, Yamaguchi A, Sato K, Nagata N, Suda T: Role of prostaglandins in interleukin-1induced bone resorption in mice in vitro. J Bone Miner Res 1991, 6:183-189

58. Gordon S: Phagocytosis: an immunobiologic process. Immunity 2016, 44:463-475

59. Mosser DM, Edwards JP: Exploring the full spectrum of macrophage activation. Nat Rev Immunol 2008, 8:958-969

60. Zhang X, Mosser DM: Macrophage activation by endogenous danger signals. J Pathol 2008, 214:161-178

61. Fang P, Li X, Dai J, Cole L, Camacho JA, Zhang Y, Ji Y, Wang J, Yang X-F, Wang H: Immune cell subset differentiation and tissue inflammation. J Hematol Oncol 2018, 11:97

62. Mills CD, Kincaid K, Alt JM, Heilman MJ, Hill AM: M-1/M-2 macrophages and the Th1/Th2 paradigm. J Immunol 2000, 164: 6166-6173

63. Klopfleisch R: Macrophage reaction against biomaterials in the mouse model: phenotypes, functions and markers. Acta Biomater 2016, 43:3-13

64. Porcheray F, Viaud S, Rimaniol A-C, Léone C, Samah B, DereuddreBosquet N, Dormont D, Gras G: Macrophage activation switching: an asset for the resolution of inflammation. Clin Exp Immunol 2005, 142:481-489

65. Ferrante CJ, Pinhal-Enfield G, Elson G, Cronstein BN, Hasko G, Outram S, Leibovich SJ: The adenosine-dependent angiogenic switch of macrophages to an M2-like phenotype is independent of interleukin-4 receptor alpha (IL-4R $\alpha$ ) signaling. Inflammation 2013, 36:921-931

66. Helming L, Gordon S: Molecular mediators of macrophage fusion. Trends Cell Biol 2009, 19:514-522

67. Mukai A, Kurisaki T, Sato SB, Kobayashi T, Kondoh G, Hashimoto N: Dynamic clustering and dispersion of lipid rafts contribute to fusion competence of myogenic cells. Exp Cell Res 2009, 315:3052-3063

68. Yagi M, Ninomiya K, Fujita N, Suzuki T, Iwasaki R, Morita K, Hosogane N, Matsuo K, Toyama Y, Suda T, Miyamoto T: Induction of DC-STAMP by alternative activation and downstream signaling mechanisms. J Bone Miner Res 2007, 22:992-1001

69. Chiu YH, Schwarz E, Li D, Xu Y, Sheu T-R, Li J, de Mesy Bentley KL, Feng C, Wang B, Wang J-C, Albertorio-Saez L, Wood R, Kim M, Wang W, Ritchlin CT: Dendritic cell-specific transmembrane protein (DC-STAMP) regulates osteoclast differentiation via the Ca2+/NFATc1 axis. J Cell Physiol 2017, 232:2538-2549

70. Van den Bossche J, Laoui D, Naessens T, Smits HH, Hokke CH, Stijlemans B, Grooten J, De Baetselier P, Van Ginderachter JA: Ecadherin expression in macrophages dampens their inflammatory responsiveness in vitro, but does not modulate M2-regulated pathologies in vivo. Sci Rep 2015, 5:12599

71. Banh $C$, Fugère $C$, Brossay L: Immunoregulatory functions of KLRG1 cadherin interactions are dependent on forward and reverse signaling. Blood 2009, 114:5299-5306
72. Fiorino C, Harrison RE: E-cadherin is important for cell differentiation during osteoclastogenesis. Bone 2016, 86:106-118

73. Taylor PR, Martinez-Pomares L, Stacey M, Lin HH, Brown GD, Gordon S: Macrophage receptors and immune recognition. Annu Rev Immunol 2005, 23:901-944

74. Jansen KM, Pavlath GK: Mannose receptor regulates myoblast motility and muscle growth. J Cell Biol 2006, 174:403-413

75. McNally AK, DeFife KM, Anderson JM: Interleukin-4-induced macrophage fusion is prevented by inhibitors of mannose receptor activity. Am J Pathol 1996, 149:975-985

76. Azad AK, Rajaram MVS, Schlesinger LS: Exploitation of the macrophage mannose receptor (CD206) in infectious disease diagnostics and therapeutics. J Cytol Mol Biol 2014, 10:1

77. Xu Z, Jin B: A novel interface consisting of homologous immunoglobulin superfamily members with multiple functions. Cell Mol Immunol 2010, 7:11-19

78. Seiffert M, Cant C, Chen Z, Rappold I, Brugger W, Kanz L, Brown EJ, Ullrich A, Bühring HJ: Human signal-regulatory protein is expressed on normal, but not on subsets of leukemic myeloid cells and mediates cellular adhesion involving its counterreceptor CD47. Blood 1999, 94:3633-3643

79. Koskinen C, Persson E, Baldock P, Stenberg A, Böstrom I, Matozaki T, Oldenborg PA, Lundberg P: Lack of CD47 impairs bone cell differentiation and results in an osteopenic phenotype in vivo due to impaired signal regulatory protein alpha (SIRPa) signaling. J Biol Chem 2013, 288:29333-29344

80. Lundberg P, Koskinen C, Baldock PA, Lothgren H, Stenberg A, Lerner UH, Oldenborg PA: Osteoclast formation is strongly reduced both in vivo and in vitro in the absence of CD47/SIRPalpha-interaction. Biochem Biophys Res Commun 2007, 352: 444-448

81. Maile LA, DeMambro VE, Wai C, Lotinun S, Aday AW, Capps BE, Beamer WG, Rosen CJ, Clemmons DR: An essential role for the association of CD47 to SHPS-1 in skeletal remodeling. J Bone Miner Res 2011, 26:2068-2081

82. Han X, Sterling H, Chen Y, Saginario C, Brown EJ, Frazier WA, Lindberg FP, Vignery A: CD47, a ligand for the macrophage fusion receptor, participates in macrophage multinucleation. J Biol Chem 2000, 275:37984-37992

83. van Beek EM, de Vries TJ, Mulder L, Schoenmaker T, Hoeben KA, Matozaki T, Langenbach GE, Kraal G, Everts V, van den Berg TK: Inhibitory regulation of osteoclast bone resorption by signal regulatory protein $\alpha$. FASEB J 2009, 23:4081-4090

84. Jurdic P, Saltel F, Chabadel A, Destaing O: Podosome and sealing zone: specificity of the osteoclast model. Eur J Cell Biol 2006, 85: 195-202

85. Wang Y, Brooks PJ, Jang JJ, Silver AS, Arora PD, McCulloch CA, Glogauer M: Role of actin filaments in fusopod formation and osteoclastogenesis. Biochim Biophys Acta 2015, 1853:1715-1724

86. Jay SM, Skokos E, Laiwalla F, Krady MM, Kyriakides TR: Foreign body giant cell formation is preceded by lamellipodia formation and can be attenuated by inhibition of Rac1 activation. Am J Pathol 2007, 171:632-640

87. Ory S, Brazier H, Pawlak G, Blangy A: Rho GTPases in osteoclasts: orchestrators of podosome arrangement. Eur J Cell Biol 2008, 87: 467-477

88. McNally AK, Anderson JM: Multinucleated giant cell formation exhibits features of phagocytosis with participation of the endoplasmic reticulum. Exp Mol Pathol 2005, 79:126-135

89. Guiet R, Verollet C, Lamsoul I, Cougoule C, Poincloux R, Labrousse A, Calderwood DA, Glogauer M, Lutz PG, MaridonneauParini I: Macrophage mesenchymal migration requires podosome stabilization by filamin A. J Biol Chem 2012, 287:13051-13062

90. Leung R, Wang Y, Cuddy K, Sun C, Magalhaes J, Grynpas M, Glogauer M: Filamin A regulates monocyte migration through Rho small GTPases during osteoclastogenesis. J Bone Miner Res 2010, 25:1077-1091 
91. Irie A, Yamamoto K, Miki Y, Murakami M: Phosphatidylethanolamine dynamics are required for osteoclast fusion. Sci Rep 2017, 7: 46715

92. Helming L, Winter J, Gordon S: The scavenger receptor CD36 plays a role in cytokine-induced macrophage fusion. J Cell Sci 2009, 122: 453-459

93. MacKenzie A, Wilson HL, Kiss-Toth E, Dower SK, North RA, Surprenant A: Rapid secretion of interleukin-1beta by microvesicle shedding. Immunity 2001, 15:825-835

94. Lemaire I, Falzoni S, Leduc N, Zhang B, Pellegatti P, Adinolfi E, Chiozzi P, Di Virgilio F: Involvement of the purinergic P2X7 receptor in the formation of multinucleated giant cells. J Immunol 2006, 177:7257-7265

95. Hwang YS, Ma GT, Park KK, Chung WY: Lysophosphatidic acid stimulates osteoclast fusion through OC-STAMP and P2X7 receptor signaling. J Bone Miner Metab 2014, 32:110-122
96. Witwicka H, Hwang SY, Reyes-Gutierrez P, Jia H, Odgren PE, Donahue LR, Birnbaum MJ, Odgren PR: Studies of OC-STAMP in osteoclast fusion: a new knockout mouse model, rescue of cell fusion, and transmembrane topology. PLoS One 2015, 10: e0128275

97. Wang N, Agrawal A, Jørgensen NR, Gartland A: P2X7 receptor regulates osteoclast function and bone loss in a mouse model of osteoporosis. Sci Rep 2018, 8:3507

98. Cho SY, Klemke RL: Purification of pseudopodia from polarized cells reveals redistribution and activation of Rac through assembly of a CAS/Crk scaffold. J Cell Biol 2002, 156:725-736

99. D’Addio SM, Baldassano S, Shi L, Cheung L, Adamson DH, Bruzek M, Anthony JE, Laskin DL, Sinko PJ, Prud'homme RK: Optimization of cell receptor-specific targeting through multivalent surface decoration of polymeric nanocarriers. J Control Release 2013, 168:41-49 